\title{
Efeito de extratos de plantas silvestres da família Solanaceae sobre o controle de Brevicoryne brassicae em couve (Brassica oleracea var. acephala) ${ }^{1}$
}

\author{
Extracts effect of wild plants of the Solanaceae family on Brevicoryne brassicae control in \\ cabbage (Brassica oleracea var. acephala)
}

\author{
Patrícia Braga Lovatto $^{2}$ Márcia Goetze ${ }^{3}$ Gladis Cleci Hermes Thomé ${ }^{4}$
}

\section{RESUMO}

\begin{abstract}
O objetivo principal deste trabalho foi testar o efeito de extratos de plantas silvestres da família Solanaceae disponíveis na região do Vale do Rio Pardo, RS, sobre o pulgãoda-couve (Brevicoryne brassicae), praga agrícola de significativa importância. Nove espécies tóxicas de Solanaceae estão disponíveis na região de estudo: seis pertencem ao gênero Solanum, uma ao gênero Brugmansia e duas são cultivadas e pertencem ao gênero Nicotiana e Capsicum. A fim de determinar a capacidade de repelência e o efeito inseticida, foram testadas as seguintes espécies: B. suaveolens (trombeteira), C. annuum var. variegated (pimenta-de-jardim), N. tabacum var. virginia (fumo), S. aculeatissimum (joá-bravo), S. americanum (ervamoura), S. diflorum (tomatinho), S. fastigiatum var. acicularium (jurubeba), S. fastigiatum var. fastigiatum (jurubeba) e $\boldsymbol{S}$. sisymbriifolium (arrebenta-cavalo). Para obtenção dos extratos foram utilizadas folhas, flores e frutos aplicando-se duas técnicas distintas de elaboração: decocção do material fresco e extração a frio do material seco. Quanto à capacidade de repelência dos extratos, os tratamentos utilizando material fresco de $\boldsymbol{S}$. fastigiatum var. acicularium (frutos verdes e maduros, $2,5 \%$ e $5 \%$ de concentração) e $\mathbf{S}$. diflorum (frutos verdes e maduros, $2,5 \%$ e $5 \%$ de concentração) demonstraram maior eficácia. Nos testes sobre a biologia do inseto os tratamentos mais eficazes como inseticida foram S. fastigiatum var. fastigiatum e var. acicularium (folhas a $10 \%$ de concentração).
\end{abstract}

Palavras-chave: Solanum, pulgão-da-couve, repelência, bioinseticida

\section{ABSTRACT}

The objective of this study was to test the effect of plant extracts from Solanaceae available in Vale do Rio Pardo region, $R S$, on the aphid Brevicoryne brassicae, agricultural pest of significant importance. Nine toxic Solanaceae species are available in the area of study: six are wild belonging to the genus Solanum, one to the genus Brugmansia, and two are cultivated and belong to the genus Nicotiana and Capsicum. To determine the repellency capacity and the insecticide effect, the following species were tested: B. suaveolens (trombeteira), C. annuum var. variegated (pimenta-de-jardim), N. tabacum var. virginia (fumo), S. aculeatissimum (joá-bravo), S. americanum (erva-moura), S. diflorum (tomatinho), S. fastigiatum var. acicularium (jurubeba), S. fastigiatum var. fastigiatum (jurubeba) and $\mathbf{S}$. sisymbriifolium (arrebenta-cavalo). The extracts were obtained from leaves, flowers and fruits applying two different extraction techniques: infusion of fresh material and cold extraction of dry material. Regarding the repellency of the extracts, the treatments using fresh material of $\mathbf{S}$. fastigiatum var. acicularium (green and ripe fruits, $2.5 \%$ and $5 \%$ concentrations) and S. diflorum (green and ripe fruits, $2.5 \%$ and $5 \%$ concentrations) had the highest effectiveness. The most effective treatments as insecticides affecting survival and reproduction were $\boldsymbol{S}$. fastigiatum var. fastigiatum and var. acicularium (leaves, 10\% concentration).

Key words: Solanum, cabbage-aphid, repellency, bio insecticide.

\section{INTRODUÇÃO}

Embora os inseticidas químicos sejam atualmente usados com relativo sucesso na agricultura, os graves problemas relacionados ao seu uso, já amplamente conhecidos, têm incentivado o desenvolvimento de métodos alternativos de controle. Além disso, o significativo incremento que esses

${ }^{1}$ Retirado do trabalho de conclusão de Curso da primeira autora para fins de obtenção do título de Bacharel em Ciências Biológicas/Ecologia. ${ }^{2}$ Biólogo, Universidade de Santa Cruz do Sul (UNISC). E-mail: biolovatto@yahoo.com.br.

${ }^{3}$ Bolsista do Programa de Iniciação Científica (PIBIC), Conselho Nacional de Desenvolvimento Científico e Tecnológico (CNPq), aluna do Curso de Ciências Biológicas/Ecologia da UNISC.

${ }^{4}$ Biólogo, Doutor, Professor Adjunto do Departamento de Biologia, UNISC. Av. Independência, 2293 sala 1206, 96815-900, Santa Cruz do Sul, RS. E-mail: gthome@unisc.br. Autor para correspondência. 
insumos representam no custo da produção agrícola, além da pressão da sociedade por produtos livres de agrotóxicos, têm exigido da pesquisa maior empenho no desenvolvimento de programas de controle biológico. Assim, várias técnicas são empregadas para o alcance do controle biológico de insetos, entre elas, a utilização de inimigos naturais como fungos, bactérias, vírus e outros insetos, ou o uso de substâncias repelentes ou inseticidas, naturalmente produzidas por algumas plantas.

Embora um número expressivo de pragas agrícolas possa ser controlado com substâncias de origem vegetal, em termos práticos, poucas pragas importantes têm sido controladas dessa forma. Alguns dos motivos são algumas limitações desses produtos, como sensibilidade aos fatores ambientais e problemas de formulação. Entretanto, um dos principais fatores é, sem dúvida, o reduzido número de substâncias identificadas e reconhecidas como eficientes agentes de controle. $\mathrm{Na}$ atualidade, as principais plantas das quais são obtidas substâncias com atividade inseticida pertencem aos gêneros Nicotiana (Solanaceae), produtoras de nicotina e nornicotina; gêneros Derris, Lonchocarpus, Tephrosia e Mundulea (Leguminoseae), produtoras de rotenóides, gênero Chrysanthemum (Asteraceae), produtoras de piretrinas e gênero Azadirachta (Meliaceae), produtoras de azadiractina (VIEIRA \& FERNANDES, 1999).

Por apresentarem metabólitos secundários com significativa toxicidade, alguns autores citam trabalhos referentes à utilização de Solanáceas como controladoras de insetos, tais como: Nicandra physaloides - contra moscas (SMITH \& DOWNS 1966); Nicotiana tabacum - contra vários insetos (VELA 1988, apud GOMERO s. d.); Datura stramonium - controle da cigarrinha verde Empoasca kraemery (GOMERO, s. d.); Lycopersicum esculentum - folhas utilizadas para o controle da mariposa branca (GOMERO, s. d.).

A busca por novos inseticidas constitui-se num campo de investigação amplo. A grande variedade de substâncias presentes na flora continua sendo um enorme atrativo na área de controle de insetos, principalmente levando-se em consideração que apenas uma pequena parcela de plantas foi investigada com tal finalidade (VIEIRA \& FERNANDES, 1999).

Nesse contexto, o presente trabalho propôs a investigação de plantas com propriedades repelentes ou inseticidas para utilização no cultivo de hortaliças da família Cruciferae, severamente atacadas pelo afídeo Brevicoryne brassicae, uma das principais pragas destes cultivos. Para tanto, foram investigadas espécies de Solanaceae, possuidoras de compostos químicos possivelmente tóxicos para $\boldsymbol{B}$. brassicae.

\section{MATERIAL E MÉTODOS}

\section{Plantas-teste}

Para identificação das Solanáceas tóxicas no ambiente utilizaram-se chaves de identificação de SMITH \& DOWNS (1966) e KISSMANN \& GROTH (1995). As coletas foram realizadas nos municípios de Candelária, Vale do Sol, Vera Cruz e Santa Cruz do Sul, na região do Vale do Rio Pardo, RS.

As espécies silvestres utilizadas para a elaboração de extratos, conforme a disponibilidade no ambiente, foram: Brugmansia suaveolens (trombeteira), Solanum americanum (erva-moura), S. aculeatissimum (joá-bravo), S. diflorum (tomatinho), S. fastigiatum var.fastigiatum (jurubeba), S. sisymbriifolium (arrebenta-cavalo) e S. fastigiatum var. acicularium (jurubeba). Ainda, utilizaram-se duas espécies cultivadas na região, Capsicum annuum var. variegated (pimenta-de-jardim) e Nicotiana tabacum var. virginia (fumo), visando comparar a atividade repelente e/ou inseticida das espécies silvestres e cultivadas. Verificou-se a disponibilidade das plantas no ambiente, assim como a condição das mesmas no período de abril de 2001 a março de 2002 . A coleta dos órgãos das espécies utilizadas foi realizada durante todo o período de observação, conforme a sua disponibilidade nas plantas.

\section{Extratos vegetais}

Para obtenção dos extratos, foram utilizados folhas, flores e frutos submetidos a duas técnicas distintas de elaboração: técnica de extração a quente por decocção do material fresco e técnica de extração a frio, após a secagem e moagem do material. Através de ambas as técnicas, foram obtidos extratos nas concentrações de $1 \%, 2,5 \%$ e $5 \%(\mathrm{p} / \mathrm{v})$.

Extração a quente - Os órgãos vegetais frescos foram misturados separadamente, por estrutura vegetal, com água deionizada na concentração de 5\% $(\mathrm{p} / \mathrm{v})$ e submetidos à fervura durante um minuto. $\mathrm{Na}$ tentativa de evitar a perda de possíveis compostos voláteis, durante a fervura, o recipiente foi vedado. Os extratos foram filtrados, resfriados e diluídos com água deionizada para a obtenção das concentrações de $2,5 \%$ e $1 \%$.

Extração a frio do material seco - Os órgãos vegetais foram secos em estufa a $60^{\circ} \mathrm{C}$ por $24 \mathrm{~h}$. Após, foram triturados até a obtenção de pó e armazenados em recipientes hermeticamente fechados e ao abrigo da luz até a sua utilização, conforme THOMAZINI et 
al. (2000). A obtenção dos extratos aquosos deu-se pela adição dos pós (separadamente, por estrutura vegetal) à água deionizada, na concentração de 5\% $(\mathrm{p} / \mathrm{v})$, sendo as misturas mantidas em frascos por 24 h para extração dos compostos hidrossolúveis. Após esse período, as misturas foram filtradas, a partir das quais foram obtidas, por diluição, as concentrações de $2,5 \%$ e $1 \%$.

\section{Praga-alvo}

O pulgão-da-couve (B. brassicae) foi a praga alvo deste trabalho. Os insetos utilizados nos bioensaios envolvendo os testes de repelência foram provenientes de cultivos independentes infestados pela "praga" (insetos selvagens). Já nos testes sobre a biologia do inseto, utilizaram-se proles controladas, provenientes de insetos do campo. Nos testes, utilizaram-se indivíduos com tamanho aproximado de $2 \mathrm{~mm}$, correspondente à fase adulta do desenvolvimento, indicada por KUBO (1993) como a mais adequada para a realização dos testes.

\section{Planta hospedeira}

Para a manutenção dos insetos artificialmente controlados, assim como para realização dos testes de repelência e biologia, utilizaram-se plantas de couve, Brassica oleracea L. var. acephala L. Almejando a obtenção de plantas com o mesmo nível nutricional para realização dos testes, optou-se por cultivar a espécie em vasos plásticos. As plantas foram tratadas com solução nutritiva e receberam solo de mesma origem. Nos testes, foram utilizadas folhas com aproximadamente $6 \mathrm{~cm}$ de largura e $7 \mathrm{~cm}$ de comprimento.

\section{Testes de repelência}

Para verificar o efeito repelente causado pelos diferentes extratos sobre os insetos, utilizou-se uma estrutura denominada ensaio de disco de folha, baseada em DE BORTOLI \& FERNANDES (1998) e VIEIRA \& FERNANDES (1999). A estrutura desenvolvida para realização dos testes de repelência constituiu-se inteiramente de peças de vidro, sendo formada por uma placa de Petri de $15 \mathrm{~cm}$ de diâmetro e frascos de vidro de $8,5 \mathrm{~cm}$ de altura e $4,5 \mathrm{~cm}$ de diâmetro. A região central da estrutura compreendeu a placa de Petri rodeada por quatro folhas de couve dispostas em sua borda. Os pecíolos das folhas permaneceram imersos dentro dos frascos de vidro contendo água. Em cada uma das folhas, foram aplicados, através de borrifador, os extratos nas concentrações de $1 \%, 2,5 \%$ e $5 \%$, além do controle (água). Em cada teste, 20 insetos foram dispostos no centro da placa sobre uma demarcação de área de 3 $\mathrm{cm}$ de diâmetro, feita com um anel plástico, permitindo o isolamento dos insetos até o início dos testes. Ao iniciá-los, o anel foi retirado e os insetos puderam transitar livremente pela placa em direção às folhas da planta hospedeira. Em intervalos de 30, 60, e 120 minutos após o início dos testes, avaliou-se o número de insetos que se deslocaram para as folhas de couve submetidas aos diferentes tratamentos. Os testes foram realizados em condições de laboratório sob luz constante em temperatura ambiente variando de 25 a $35^{\circ} \mathrm{C}$. Para cada tratamento foram feitas três repetições.

\section{Testes de conservação dos extratos}

Foram realizados testes de conservação dos extratos elaborados através da técnica de decocção do material fresco. Para tanto, os extratos aquosos foram armazenados em frascos revestidos por papel alumínio, em geladeira com temperatura de $4 \pm 1^{\circ} \mathrm{C}$ durante o período de 30 dias. Após esse período, verificou-se sua efetividade perante a realização de novos testes de repelência.

\section{Testes sobre a biologia dos insetos}

Para realização dos testes sobre a biologia do inseto, utilizaram-se proles controladas a partir de insetos selvagens. Para isso, os insetos selvagens, provenientes de cultivos independentes, foram isolados individualmente em placas de Petri e colocados sobre folhas de couve, mantidas túrgidas com algodão hidrófilo umedecido. Após identificação, as placas foram envolvidas por filme de PVC impedindo, assim, a saída ou entrada de insetos. Em uma incubadora, os pulgões foram submetidos a condições artificiais propícias para o seu desenvolvimento, tais como: temperatura constante de $25^{\circ} \mathrm{C}$ e fotoperíodo de $12 \mathrm{~h}$. Após $24 \mathrm{~h}$, verificou-se a presença de ninfas nas placas, que posteriormente foram utilizadas para a realização dos testes envolvendo a biologia do inseto.

Para avaliar a biologia do inseto, utilizouse os tratamentos mais eficientes nos testes de repelência (folhas de $\boldsymbol{S}$. fastigiatum var. acicularium a $2,5 \%$ e fruto verde de S. diflorum a 2,5\%), elaborados através da primeira técnica. Além das concentrações mais eficientes, testou-se, também, uma concentração mais elevada (10\%). Ainda, utilizou-se quatro espécies ineficientes nos ensaios de repelência para realização dos testes sobre a biologia do inseto: folhas de $B$. suaveolens, fruto verde de $\boldsymbol{S}$. aculeatissimum, folhas de S. fastigiatum var. fastigiatum e folhas de N. tabacum var. virginia todos 
na concentração de $10 \%$. Ninfas com idade conhecida (um dia de vida) foram colocadas sobre folhas de couve de mesmo tamanho e nível nutricional, provenientes do cultivo controlado. As folhas com os insetos foram pulverizadas com os extratos ou água deionizada (controle). Para cada tratamento, utilizaram-se 10 repetições. Após a pulverização, os pecíolos da couve foram envolvidos com algodão hidrófilo umedecido, e as folhas foram colocadas em placa de Petri. Depois de vedadas com filme de PVC, as placas foram mantidas em incubadora sob temperatura constante de $25^{\circ} \mathrm{C}$ e fotofase de $12 \mathrm{~h}$ durante 20 dias, tempo médio do ciclo de vida do pulgão a essa temperatura. A cada 24h, após o início dos testes, foram feitas avaliações com auxílio de microscópio estereoscópico, observando: número de ninfas produzidas pelo inseto na fase adulta; ocorrência de mudas (ecdise), através da identificação e contagem de exúvias; mortalidade dos insetos e eventuais anormalidades nos mesmos. A cada avaliação, a placa de Petri e o algodão foram trocados, evitando, assim, o acúmulo de umidade e conseqüentemente o apodrecimento da folha hospedeira. Sempre que avaliada a presença de exúvias e ninfas, estas eram retiradas da folha hospedeira evitando-se, assim, confusões e interferências nos testes, relacionadas à data de ocorrência e à origem das mesmas.

\section{Análise dos dados}

Os extratos vegetais foram avaliados quanto à sua ação repelente, observada através da opção feita pelos próprios insetos expostos aos diferentes tratamentos, e ação inseticida, avaliada conforme a ocorrência de mudas (ecdises), e sobrevivência de ninfas. Os dados obtidos nos testes de repelência e biologia foram submetidos à transformação por raiz quadrada $(\sqrt{x+1})$, a fim de homogeneizar as variâncias. Depois de transformados, os dados foram submetidos à análise de variância e as médias separadas pelo teste de Duncan a 5\% de probabilidade de erro.

\section{RESULTADOS E DISCUSSÃO}

\section{Disponibilidade de Solanáceas no campo}

As plantas silvestres disponíveis na região investigada constituem sete espécies, destas, seis pertencem ao gênero Solanum e uma ao gênero Brugmansia. Segundo SACCO et al. (1985), o gênero Solanum é o mais representativo da família Solanaceae, tanto em número de plantas úteis ao homem como plantas nocivas. Segundo KISSMANN \& GROTH (1995), o gênero Brugmansia tem como uma de suas características importantes a presença de compostos tóxicos. As sete espécies encontradas foram explicitadas no item anterior.

\section{Testes de repelência utilizando extratos elaborados a partir de material fresco - decocção}

A espécie 4 ( $\boldsymbol{S}$. fastigiatum var. acicularium) apresentou os resultados mais satisfatórios em relação a repelência de insetos, quando comparada ao controle (Tabela 1). Para essa espécie, os tratamentos mais eficientes foram os elaborados

Tabela 1 - Médias do número de insetos nos testes de repelência quando utilizados extratos de Solanáceas obtidos através da técnica de decocção - material fresco.

\begin{tabular}{|c|c|c|c|c|c|c|c|c|c|}
\hline \multicolumn{10}{|c|}{ Espécies \# } \\
\hline Órgãos & 1 & 2 & 3 & 4 & 5 & 6 & 7 & 8 & 9 \\
\hline Folha & $2,58 \mathrm{a}^{1}$ & $2,25 \mathrm{a}$ & $1,63 \mathrm{a}$ & $1,91 \mathrm{a}$ & $1,63 \mathrm{a}$ & $3,58 \mathrm{a}$ & $1,09 \mathrm{~b}$ & $2,91 \mathrm{a}$ & $1,75 \mathrm{~b}$ \\
\hline Flor & - & $1,81 \mathrm{a}$ & - & $2,75 \mathrm{a}$ & $0,81 \mathrm{a}$ & - & $1,72 \mathrm{ab}$ & $1,75 \mathrm{a}$ & - \\
\hline Fruto verde & $2,00 \mathrm{a}$ & - & $2,63 \mathrm{a}$ & $1,54 \mathrm{~b}$ & - & $1,50 \mathrm{~b}$ & $2,27 \mathrm{ab}$ & $2,72 \mathrm{a}$ & $3,33 \mathrm{a}$ \\
\hline Fruto maduro & $2,33 \mathrm{a}$ & - & $2,75 \mathrm{a}$ & $1,36 \mathrm{~b}$ & - & $1,72 \mathrm{~b}$ & $2,75 \mathrm{a}$ & $2,08 \mathrm{a}$ & $3,41 \mathrm{a}$ \\
\hline \multicolumn{10}{|c|}{ Concentração } \\
\hline Controle & $3,11 \mathrm{a}$ & $2,00 \mathrm{a}$ & $2,00 \mathrm{a}$ & $3,45 \mathrm{a}$ & $1,20 \mathrm{a}$ & $3,87 \mathrm{a}$ & $2,10 \mathrm{a}$ & $2,09 \mathrm{a}$ & $3,00 \mathrm{ab}$ \\
\hline $1 \%$ & $1,55 \mathrm{~b}$ & $3,00 \mathrm{ab}$ & $2,44 \mathrm{a}$ & $2,83 \mathrm{a}$ & $2,00 \mathrm{a}$ & $2,22 \mathrm{ab}$ & $2,27 \mathrm{a}$ & $2,25 \mathrm{a}$ & $3,77 \mathrm{a}$ \\
\hline $2,5 \%$ & $2,00 \mathrm{ab}$ & $1,83 a b$ & $1,50 \mathrm{a}$ & $0,58 \mathrm{~b}$ & $0,50 \mathrm{a}$ & $1,44 \mathrm{~b}$ & $1,41 \mathrm{a}$ & $2,50 \mathrm{a}$ & $2,55 \mathrm{ab}$ \\
\hline $5 \%$ & $2,55 \mathrm{ab}$ & $1,33 \mathrm{~b}$ & $3,33 \mathrm{a}$ & $0,81 \mathrm{~b}$ & $1,33 \mathrm{a}$ & $1,77 \mathrm{~b}$ & $2,16 \mathrm{a}$ & $2,58 \mathrm{a}$ & $2,00 \mathrm{~b}$ \\
\hline $\mathrm{CV}(\%)$ & 25,0 & 22,1 & 28,4 & 25,9 & 27,5 & 24,3 & 25,3 & 27,3 & 22,4 \\
\hline
\end{tabular}

${ }^{1}$ médias não seguidas por letras iguais, comparadas nas colunas correspondentes a órgão ou concentração, diferem significativamente segundo o teste de Duncan a 5\% de probabilidade de erro.

- testes não realizados por insuficiência de material disponível.

\# espécies: 1 (Solanum aculeatissimum), 2 (Nicotiana tabacum var. virginia), 3 (S. americanum), 4 (S. fastigiatum var. acicularium), 5 (Brugmansia suaveolens), 6 (S. diflorum), 7 (S. fastigiatum var. fastigiatum), 8 (S. sisymbriifolium), 9 (Capsicum annuum var. variegated). 
com frutos verdes e maduros a $2,5 \%$ e $5 \%$ de concentração. A espécie 6 (S. diflorum) também pode ser indicada como repelente, sendo que os tratamentos mais eficientes foram os elaborados com frutos verdes e maduros a $2,5 \%$ e $5 \%$.

Conforme COSTA (1994), as espécies $S$. fastigiatum var. acicularium e $S$. diflorum possuem alcalóides esteroidais que, nessas plantas, estão sob a forma de jurubina e solanocapsina. Segundo ROBBERS et al. (1996), essas substâncias são capazes de desencadear atividades antimicrobianas, antifúngicas e nocivas a muitos insetos e moluscos. Ainda se tem observado nos alcalóides esteroidais atividade deterrente de alimentação e tóxica contra a maioria dos insetos (SANFORD et al., 1996).

A espécie 1 ( $S$. aculeatissimum) não apresentou diferenças estatisticamente significativas quando comparadas as médias dos seus respectivos órgãos. Já quanto às concentrações dos extratos desta espécie, a mais eficiente, foi a concentração de $1 \%$. Entretanto, considerando a ineficiência das concentrações $2,5 \%$ e $5 \%$, em repelir os insetos, não se deve considerar este resultado, pois a eficácia do extrato a $1 \%$, na verdade parece ser resultado da ação atraente sobre os insetos apresentada pelos extratos de maior concentração.

A espécie 2 (N. tabacum) não apresentou diferenças significativas quando comparadas as médias dos órgãos testados. Por outro lado, conforme a análise referente às concentrações, houve repelência significativa na maior concentração (5\%). Acredita-se que a alta capacidade de volatilização dos compostos tóxicos da espécie, assim como as concentrações utilizadas, tenham interferido nos resultados, já que esta espécie é bastante citada como repelente. Cabe lembrar, ainda, que os compostos químicos dessa espécie são altamente tóxicos para os mamíferos, tornando a utilização de concentrações maiores um problema considerável na aplicação de extratos da planta para o controle biológico. Além disso, quantidades significativas de insumos químicos são normalmente aplicadas nos cultivos da espécie, tornando sua utilização para o controle biológico inadequada.

Embora tenha havido diferenças significativas entre os órgãos das espécies 7 ( $S$. fastigiatum var. fastigiatum) e 9 (C. annuum var. variegated), nenhuma das concentrações dos extratos testados foram significativamente diferentes do controle e, portanto, nenhum deles pode ser considerado efetivo.

As demais espécies testadas não apresentaram diferenças significativas entre os órgãos e as concentrações dos extratos, portanto, podem ser 0consideradas ineficazes quanto à ação repelente sobre os insetos.

Teste de conservação dos extratos elaborados a partir de material fresco

Os resultados obtidos nos testes de repelência, após 30 dias de armazenamento dos extratos em geladeira, revelaram acelerada deterioração, influenciando assim, a sua eficiência e confundindo os resultados em conseqüência do intenso odor liberado pelas substâncias. Dessa forma, considera-se inviável a aplicação dos mesmos após o armazenamento nas condições testadas, sendo proposta a elaboração e aplicação imediata dos extratos nos cultivos.

Testes de repelência utilizando extratos elaborados a partir de material seco

Comparando os dados da tabela 2 com aqueles apresentados na tabela 1 constatou-se que o valor absoluto das médias é bem mais alto, sendo que, de um modo geral, observou-se um efeito atrativo dos extratos sobre os insetos. A espécie 8 ( $\boldsymbol{S}$. sisymbriifolium) foi a única na qual se observou repelência significativa para as concentrações testadas, (maior concentração, em relação à testemunha), sendo que o tratamento elaborado com flores a $5 \%$ foi o mais eficiente. Testes extras devem ser realizados para confirmar estes resultados, pois, conforme SCHENKEL et al. (1999), essa espécie possui um glicoalcalóide esteroidal do tipo solamina de toxicidade comprovada.

Acredita-se que alguns fatores tenham contribuído para a ineficiência da maioria dos tratamentos envolvendo extratos elaborados a partir desta técnica. Entre eles, destacam-se provavelmente a volatilização de alguns compostos químicos presentes nas plantas e a temperatura do solvente (água). Buscando minimizar as dúvidas existentes em relação a esses resultados, repetiram-se os testes utilizando extratos elaborados com solvente (água) quente, como na técnica de decocção. Os tratamentos mais uma vez demonstraram-se ineficientes, tornando a primeira hipótese, a volatilização dos compostos tóxicos durante a secagem na estufa, a mais aceita como justificativa para a ineficiência dos mesmos.

\section{Influência dos extratos sobre a biologia do inseto}

Na tabela 3, são apresentados os dados quanto à média de sobrevivência dos insetos em cada um dos tratamentos. Os tratamentos 4 (folhas de $\boldsymbol{S}$. fastigiatum var. fastigiatum a $10 \%$ ) e 2 (folhas de $\boldsymbol{S}$. fastigiatum var. acicularium a 10\%), foram os 
Tabela 2 - Médias do número de insetos nos testes de repelência quando utilizados extratos de Solanáceas obtidos através da técnica de extração a frio - material seco

\begin{tabular}{|c|c|c|c|c|c|c|c|c|c|}
\hline \multicolumn{10}{|c|}{ Espécies \# } \\
\hline Órgãos & 1 & 2 & 3 & 4 & 5 & 6 & 7 & 8 & 9 \\
\hline Folha & $3,60 \mathrm{a}^{1}$ & $2,58 \mathrm{a}$ & $1,22 \mathrm{~b}$ & $3,90 \mathrm{a}$ & $3,18 \mathrm{a}$ & $3,72 \mathrm{a}$ & $3,72 \mathrm{a}$ & $4,54 \mathrm{a}$ & $2,90 \mathrm{a}$ \\
\hline Flor & - & $3,91 \mathrm{a}$ & - & $2,80 a b$ & $3,16 \mathrm{a}$ & - & $2,55 \mathrm{a}$ & $2,83 \mathrm{~b}$ & - \\
\hline Fruto verde & $3,70 \mathrm{a}$ & - & $2,90 \mathrm{a}$ & $1,45 \mathrm{~b}$ & - & $4,44 \mathrm{a}$ & $4,41 \mathrm{a}$ & $4,40 \mathrm{a}$ & $2,81 \mathrm{a}$ \\
\hline Fruto maduro & $3,11 \mathrm{a}$ & - & $3,33 \mathrm{ab}$ & $3,36 \mathrm{a}$ & - & $4,25 \mathrm{a}$ & $4,18 \mathrm{a}$ & $5,10 \mathrm{a}$ & $3,25 \mathrm{a}$ \\
\hline \multicolumn{10}{|c|}{ Concentração } \\
\hline Controle & $2,14 \mathrm{~b}$ & $2,66 \mathrm{a}$ & $2,75 \mathrm{a}$ & $2,09 \mathrm{bc}$ & $2,66 \mathrm{ab}$ & $4,12 b$ & $3,30 \mathrm{~b}$ & $5,36 \mathrm{a}$ & $2,44 \mathrm{cb}$ \\
\hline $1 \%$ & $3,28 \mathrm{ab}$ & $2,66 \mathrm{a}$ & $3,25 \mathrm{a}$ & $4,90 \mathrm{a}$ & $5,00 \mathrm{a}$ & $7,25 \mathrm{a}$ & $5,45 \mathrm{a}$ & $5,20 \mathrm{a}$ & $3,75 \mathrm{ab}$ \\
\hline $2,5 \%$ & $4,14 \mathrm{ab}$ & $4,33 \mathrm{a}$ & $2,14 \mathrm{a}$ & $3,50 \mathrm{ab}$ & $3,66 a b$ & $1,50 \mathrm{c}$ & $3,63 a b$ & $3,90 \mathrm{ab}$ & $4,71 \mathrm{a}$ \\
\hline $5 \%$ & $4,25 \mathrm{a}$ & $3,33 \mathrm{a}$ & $1,66 \mathrm{a}$ & $1,41 \mathrm{c}$ & $1,66 \mathrm{~b}$ & $3,62 \mathrm{bc}$ & $2,72 \mathrm{~b}$ & $2,27 \mathrm{~b}$ & $1,55 \mathrm{c}$ \\
\hline C. V. $(\%)$ & 21,7 & 33,0 & 25,3 & 25,9 & 22,5 & 24,7 & 23,2 & 20,5 & 18,4 \\
\hline
\end{tabular}

${ }^{1}$ médias não seguidas por letras iguais, comparadas nas colunas correspondem a órgão ou concentração, diferem significativamente segundo o teste de Duncan a $5 \%$ de probabilidade de erro.

- testes não realizados por insuficiência de material disponível.

\# espécies: 1 (Solanum aculeatissimum), 2 (Nicotiana tabacum var. virginia), 3 (S. americanum), 4 (S. fastigiatum var. acicularium), 5 (Brugmansia suaveolens), 6 (S. diflorum), 7 (S. fastigiatum var. fastigiatum), 8 (S. sisymbriifolium), 9 (Capsicum annuum var. variegated).

responsáveis pelas médias de vida mais baixas. Esses resultados demonstram uma diferença significativa entre a reação olfativa e a reação de contato apresentada pelos extratos sobre os insetos, já que a espécie mais eficiente como inseticida está entre as que não apresentaram efeito significativo de repelência. Assim, a capacidade repelente não pode ser relacionada com a ação inseticida das substâncias, pois estas possuem ação sobre diferentes receptores nos insetos. Além disso, constatouse que o número de ninfas produzido pelos pulgões adultos (Tabela 4) dependeu do tempo de sobrevivência do pulgão. Comparando-se os dados das tabelas 3 e 4, pode-se observar que os tratamentos em que os pulgões produziram menor números de ninfas, também foram aqueles onde sobreviveram por menor tempo e vice-versa. Assim, todos os pulgões que completaram quatro ecdises, produziram pelo menos uma ninfa; já os que não sobreviveram por tempo necessário para finalização das quatro ecdises não apresentaram produção de ninfas. Desse modo, os tratamentos 2, 4 e 10 que apresentaram as menores médias de sobrevivência não produziram ninfas; já os tratamentos 5,8 e o controle apresentaram as maiores médias de sobrevivência e conseqüentemente uma maior produção de ninfas.

Os tratamentos 3, 5, 8, 9, 11 e 12 (Tabela 4) parecem não ter afetado o desenvolvimento reprodutivo dos pulgões, já que os pulgões que sobreviveram aos tratamentos foram capazes de se reproduzir aparentemente de forma normal. Analisando os resultados (Tabelas 3 e 4), pode-se considerar como efetivos apenas os tratamentos 1,2, 4, 6, 7 e 10, pois estes demonstraram efeito inseticida não permitindo a evolução do inseto para fase adulta e com isso impedindo sua reprodução. As espécies 1, 2, 4 e 6 possuem alcalóides esteroidais tóxicos para insetos e outros invertebrados (SANFORD et al. 1996). A espécie 7 possui o princípio tóxico nas sementes, parecendo ser uma solamina de ação irritante

Tabela 3 - Sobrevivência média (nº de dias) de $\boldsymbol{B}$. brassicae nos diferentes tratamentos.

\begin{tabular}{ll}
\hline \multicolumn{1}{c}{ Tratamentos } & $\begin{array}{c}\text { Sobrevivência } \\
\text { (dias) }\end{array}$ \\
\hline 1- Solanum fastigiatum var. acicularium (folha 2,5\%) & $2,0 \mathrm{de}^{1}$ \\
2- Solanum fastigiatum var. acicularium (folha 10\%) & $1,7 \mathrm{e}$ \\
3- Solanum fastigiatum var. fastigiatum (folha 2,5\%) & $2,8 \mathrm{de}$ \\
4- Solanum fastigiatum var. fastigiatum (folha 10\%) & $1,4 \mathrm{e}$ \\
5- Solanum diflorum (fruto verde 2,5\%) & $9,0 \mathrm{a}$ \\
6- Solanum diflorum (fruto verde10\%) & $2,4 \mathrm{de}$ \\
7- Solanum aculeatissimum (fruto verde 1\%) & $3,3 \mathrm{cde}$ \\
8- Solanum aculeatissimum (fruto verde 10\%) & $6,8 \mathrm{ab}$ \\
9- Nicotiana tabacum (folha 5\%) & $2,3 \mathrm{de}$ \\
10- Nicotiana tabacum (folha 10\%) & $1,9 \mathrm{de}$ \\
11- Brugmansia suaveolens (folha 2,5\%) & $4,7 \mathrm{bcd}$ \\
12- Brugmansia suaveolens (folha 10\%) & $2,1 \mathrm{de}$ \\
13- Controle ( ${ }_{2} \mathrm{O}$ ) & $6,2 \mathrm{abc}$ \\
CV (\%) & \\
\hline
\end{tabular}

${ }^{1}$ médias não seguidas por letras iguais diferem significativamente segundo o teste de Duncan a 5\% de probabilidade de erro. 
Tabela 4 - Número de ninfas de pulgão-da couve produzidas nos diferentes tratamentos testados.

\begin{tabular}{|c|c|c|}
\hline Tratamentos & № de matrizes* & № total de ninfas \\
\hline 1- Solanum fastigiatum var. acicularium (folhas 2,5\%) & - & - \\
\hline 2- Solanum fastigiatum var. acicularium (folhas 10\%) & - & - \\
\hline 3- Solanum fastigiatum var. fastigiatum (folhas 2,5\%) & 1 & 24 \\
\hline 4- Solanum fastigiatum var. fastigiatum (folhas $10 \%$ ) & - & - \\
\hline 5- Solanum diflorum (fruto verde $2,5 \%$ ) & 4 & 127 \\
\hline 6- Solanum diflorum (fruto verde $10 \%$ ) & - & - \\
\hline 7- Solanum aculeatissimum (fruto verde 1\%) & - & - \\
\hline 8- Solanum aculeatissimum (fruto verde 10\%) & 2 & 62 \\
\hline 9- Nicotiana tabacum (folhas 5\%) & 1 & 12 \\
\hline 10- Nicotiana tabacum (folhas $10 \%$ ) & - & - \\
\hline 11-Brugmansia suaveolens (folhas $2,5 \%$ ) & 3 & 18 \\
\hline 12-Brugmansia suaveolens (folhas $10 \%$ ) & 1 & 22 \\
\hline 13- Controle $\left(\mathrm{H}_{2} \mathrm{O}\right)$ & 5 & 90 \\
\hline
\end{tabular}

$* n^{o}$ inicial de pulgões por tratamento $=10$. Somente pulgões que completaram quatro ecdises produziram ninfas.

(SCHUARTSMAN, 1979). Já a espécie 10 é bastante conhecida pelo seu alcalóide majoritário, a nicotina, que, segundo MARICONI (1983), é utilizada como inseticida de contato, fumigante e de ingestão.

Cabe destacar, que com a realização desta pesquisa, pretendeu-se contribuir para a formulação de novos compostos repelentes e/ou inseticidas, extraídos de plantas, visando a produção orgânica e a conservação ambiental.

\section{CONCLUSÕES}

S. fastigiatum var. acicularium, dentre outras plantas testadas, é a espécie mais eficiente para repelir o pulgão Brevicoryne brassicae, quando pulverizada sob a forma de extratos, obtidos a partir de material fresco, sobre as plantas hospedeiras, e com potencial inseticida quando aplicada sobre o inseto em condições controladas. Esta espécie foi eficaz como repelente quando foram utilizados frutos verdes e maduros para a elaboração dos extratos a 2,5 e 5\% de concentração. Como inseticida, essa espécie foi eficaz quando o extrato foi elaborado a partir de folhas a $10 \%$ de concentração.

S. fastigiatum var. fastigiatum é a espécie que mais afeta a sobrevivência dos insetos, no entanto, não é eficiente como repelente.

\section{REFERÊNCIAS BIBLIOGRÁFICAS}

COSTA, F.A. Farmacognosia. 4.ed. Lisboa : Fundação Calouste Gulbenkian, 1994. V.2, 1117p.

DE BORTOLI, A.S.; FERNANDES, M.C. Atratividade de Brevicoryne brassicae (L., 1758) (Homoptera, Aphididae) a plantas de couve (Brassica oleracea L. var. acephala) nutridas com diferentes níveis de nitrogênio. In: CONGRESSO BRASILEIRO DE ENTOMOLOGIA, 17., 1998, Rio de Janeiro. Anais... Rio de Janeiro : UFRJ, 1998. p.400.

GOMERO, O.L. (Ed.). Plantas para proteger cultivos. Lima : Red de Acción en Alternativas al Uso de Agroquímicos, (s. d.). 239p.

KISSMANN, K.G.; GROTH D. Plantas infestantes e nocivas: Plantas superiores - Dicotiledôneas. São Paulo : Basf, 1995. Tomo III, 683p.

KUBO, I. Insect control agents from tropical plants. In: DOWNUM, K.R.; ROMEO, J.T.; STAFFORD, H.A. (ed). Recent advances in phytochemistry: phytochemical potential of tropical plants. New York : Plenum, 1993. 133p.

MARICONI, F.A.M. Inseticidas e seu emprego no combate às pragas. 7.ed. São Paulo: Nobel, 1983. Tomo II, 466p.

ROBBERS, E.J.; SPEEDIE K.M.; TYLER, E.V. Farmacognosia e biotecnologia. São Paulo : Premier, 1996. 372p.

SACCO, J. da C. et al. Ervas daninhas do Brasil. Solanaceae I. Gênero Solanum $L$. Brasília : EMBRAPA-DDT (EMBRAPACNPDA), 1985. 58p. (Documentos, 1).

SANFORD, L.L. et al. Mortality of potato leafhopper adults on synthetic diets containing seven glycoalkaloids synthesized in the foliage of various Solanum species. Potato Journal, v.73, p.79$88,1996$.

SCHENKEL, E.P. et al. Plantas tóxicas. In: SIMÕES, C.M. et al. (Org.). Farmacognosia - da planta ao medicamento. Porto Alegre/Florianópolis : UFRGS/UFSC, 1999. p.785788 .

SCHUARTSMAN, S. Plantas venenosas. São Paulo Sorvier, 1979. 176p.

SMITH, L.B.; DOWNS, R.J. Flora ilustrada catarinens: Solanáceas. Itajaí : Herbário Barbosa Rodrigues, 1966. 321p.

Ciência Rural, v. 34, n.4, jul-ago, 2004. 
THOMAZINI, A.P.B.W.; VENDRAMIM, J.D.; LOPES, M.T.R. Extratos Aquosos de Trichilia pallida e a Traça-doTomateiro. Scientia Agrícola, v.57, n.1, p.13-17, mar, 2000.
VIEIRA, C.P.; FERNANDES, B.J. Plantas inseticidas. In: SIMÕES, C.M. et al. (Org.). Farmacognosia - da planta ao medicamento. Porto Alegre/Florianópolis : UFRGS/UFSC, 1999. p.739-754. 